\title{
BMJ Open Associations between maternal social capital and infant birth weight in three developing countries: a cross-sectional multilevel analysis of Young Lives data
}

\author{
Hwa-Young Lee (D) ,1,2 Juhwan Oh, ${ }^{1,3}$ Jessica M Perkins (D) ,, Jongho Heo (D) ,,6 \\ S V Subramanian ${ }^{3,7}$
}

To cite: Lee $\mathrm{H}-\mathrm{Y}, \mathrm{Oh} \mathrm{J}$, Perkins JM, et al. Associations between maternal social capital and infant birth weight in three developing countries: a crosssectional multilevel analysis of Young Lives data. BMJ Open 2019;9:e024769. doi:10.1136/ bmjopen-2018-024769

- Prepublication history and additional material for this paper are available online. To view these files, please visit the journal online (http://dx.doi. org/10.1136/bmjopen-2018024769).

Received 21 June 2018 Revised 05 September 2019 Accepted 12 September 2019

Check for updates

(c) Author(s) (or their employer(s)) 2019. Re-use permitted under CC BY-NC. No commercial re-use. See rights and permissions. Published by BMJ.

For numbered affiliations see end of article.

Correspondence to

Dr Juhwan Oh;

oh328@snu.ac.kr

\section{ABSTRACT}

Objective To explore how three indicators of social capital (ie, group membership, social support and cognitive social capital and specific types within each type) are associated with infant birth weight.

Study design and settings Cross-sectional analyses of the first wave of Young Lives Survey data collected in 2002 from India (Andhra Pradesh state), Peru and Vietnam. Participants 807 mothers in India, 1528 mothers in Peru and 1706 mothers in Vietnam.

Outcomes measure Infant birth weight was measured in grams. Participation in specific groups, receipt of social support from specific groups or individuals and perceptions of their community were measured for social capital indicators. Two-level random intercept linear regression models were fit separately by country (first level: individual and second level: community).

Results Maternal group membership displayed a consistent positive association with infant birth weight across the three countries. There was no relationship with maternal cognitive social capital. Membership in a women's group was associated with infant birth weight consistently in all three countries $(b=119.6,95 \% \mathrm{Cl}$ 21.7 to 217.4 in India, $b=133.4,95 \% \mathrm{Cl} 40.9$ to 225.9 in Peru, $b=60.6,95 \% \mathrm{Cl} 0.5$ to 120.6 in Vietnam). However, membership in a political group in Peru was inversely associated with infant birth weight $(b=-276.1,95 \% \mathrm{Cl}$ -465.7 to -86.5$)$.

Conclusion Although a higher level of social capital is associated with higher infant birth weight, specific types of social capital may have different associations with infant birth weight depending on the social, political or cultural specificity of the country. These results pave the way for additional research on the mechanisms through which social capital influences birth weight outcomes in each country.

\section{INTRODUCTION}

Infants born with low birth weight are more likely to have disabilities and be hospitalised, ${ }^{1}$ or display intellectual impairment. ${ }^{2}$ These challenges have been linked to lower socioeconomic status (SES) and chronic diseases later in life. ${ }^{3}$ In addition, most low birth weight babies require high-cost intensive care
Strengths and limitations of this study

- This study comprehensively explored the mutually adjusted associations between three dimensions of maternal social capital and infant birth weight across multiple low-income and middle-income countries (LMICs): India, Peru and Vietnam.

- The relationships between infant birth weight and specific components of social group membership and social support were further assessed.

- Data represented randomly sampled mothers and children across Peru and Vietnam and across the state of Andhra Pradesh in India with an oversampling of poor sites.

- The study design is cross-sectional so causality cannot be inferred between social capital and infant birth weight.

- Maternal clinical data were not available, which may lead to omitted variable bias. Data are more than 15 years old. However, our message is still valid and can give lessons to other LMICs that are currently going through similar contexts.

technology right after birth as well as continuous medical care, causing a substantial economic burden to society. ${ }^{45}$

Many studies over the last few decades focusing on factors associated with low birth weight have found that the determinants of low birth weight are multifactorial. ${ }^{6}$ For example, intrauterine growth restriction due to congenital anomalies ${ }^{7}$ and environmental factors (eg, exposure to tobacco smoking or environmental toxins) cause low birth weight. ${ }^{89}$ SES and health behaviours such as smoking, alcohol consumption and missing prenatal care have also been associated with low infant birth weight. ${ }^{10-12}$ In addition, social capital has been identified as an important correlate of pregnancy and infant health outcomes even after adjusting for socioeconomic characteristics. ${ }^{13-16}$ These factors are not necessarily mutually exclusive as one 
factor may influence infant birth weight either directly or indirectly through another factor. ${ }^{17}$

Public health research has generally conceptualised the term social capital in two ways. ${ }^{18}$ 'Social-cohesion' school of thought presents social capital as a group-level attribute of an organisation or a community, as opposed to a description of individual members who belong to the group. ${ }^{19-21}$ They recognise social capital as a functional dimension generated from the social structure of society, communities or neighbourhoods, while social supports are different functional dimension generated from a social network of individual actors within the social structure ${ }^{20}$ Another school of thought, 'network' theory of social capital' defines social capital in terms of the resources embedded within whole social networks. Under this framework, social capital can be assessed as both an individual attribute as well as a property of the collective. ${ }^{22-24}$ Individual-level attributes of social capital can be measured as an individual's access to instrumental, emotional or financial support within a social network, and group-level attributes of social capital, named 'cognitive social capital', can be measured as collective norms, attitudes, beliefs and values.

Technically, network structure could be described as a structural factor that generates social support and social capital rather than being categorised itself as social capital. ${ }^{20}$ However, network structure is also used as a measure of social capital by some researchers, ${ }^{25}$ for example, as a count of connections to individuals and groups or the strength of those connections. Specifically, a stronger or larger social network can provide pregnant mothers with access to information in addition to being associated with higher cognitive social capital as well as social support. ${ }^{16}$ Our study adopted the 'network' analyst view on the conceptualisation of social capital with social network being included as social capital.

The mechanisms linking maternal social support and infant health have been relatively well established in previous studies. Maternal social support operates directly by motivating the mother to engage in positive health behaviours via knowledge transfer or receipt of financial aid from the social supports. ${ }^{26}$ It can also affect infant health indirectly by buffering against stressful life transitions. ${ }^{27-29}$ Another possible explanation is that social support stimulates beneficial neuroendocrine responses. ${ }^{30}$ In addition, feelings of security and self-esteem produced through high cognitive social capital may affect pregnancy outcomes by reducing mental stress or adjusting health behaviours. ${ }^{31}{ }^{32}$ However, most prior studies have focused on either only one of dimension of social capital or have aggregated the different dimensions of social capital into one index, ${ }^{143}$ despite other studies emphasising the importance of separating the dimensions of social capital. ${ }^{22}{ }^{34}$ In addition, most of this research was based in high-income countries, such as the $\mathrm{UK},{ }^{35} \mathrm{USA}^{36-38}$ and the Netherlands. ${ }^{14}$

Another missing point in previous studies is that they either focused on only one specific type of social capital or used composite score, ${ }^{14}{ }^{33}$ although each type of social network or social support may play a different role in infant birth outcomes. None has comprehensively assessed the differential associations that specific types of social capital may exhibit with infant birth weight.

To address these gaps in the literature, this study aimed to: (1) explore the associations between infant birth weight and level of maternal social network, cognitive social capital and social support and (2) explore the association between different types of social capital and infant birth weight in three low-income or middle-income countries (India, Peru and Vietnam). We hypothesised each of the three dimensions of social capital individual mothers have would be positively associated with infant birth weight but that the specific types in each dimension of social capital will exhibit different pattern of the associations with infant birth weight.

\section{METHODS}

\section{Data source}

Data were obtained from an international and longitudinal survey named 'Young Lives study'. ${ }^{39}$ The Young Lives study is composed of two cohort groups. The 'younger cohort' representing 2011, 2052 and 2002 children aged 6-18 months in 2002 (representing the first wave of data) in India, Peru and Vietnam, respectively. Although more recent waves of data were collected, this study uses the data from 2002 because that first round is when infant birth weight was recorded and when the maternal social capital assessments were most temporally close to infant birth weight compared with more recent rounds of data collection.

The Young Lives study employed a clustered sampling strategy with a semipurposive sampling of 20 sentinel sites in each country to represent a range of regions, policy contexts and living conditions with oversampling of poor sites to serve the study objective, which is to study the causes and consequences of childhood poverty. ${ }^{39}$ All households with children aged between 6 months and 18 months within the sites were listed, and then 100 households from each site were randomly selected for the survey. ${ }^{40}$ More information on the sampling strategies in each country can be found elsewhere. ${ }^{41}$ Households that refused to participate-less than $2 \%$ of the selected households-were replaced with other households from the list. The response rate was above $90 \%$ in all the countries. Data were collected by a standardised, interviewer-administered questionnaire from the child's main caregiver. All interviewers received training based on common guidelines.

After excluding 'non-biological mothers' and 'missing' and 'don't know' responses in the outcome and independent variables, the number of respondents in the final analytic sample was 807 mother/child pairs residing in 95 communities in India, 1528 pairs in 82 communities in Peru and 1706 pairs in 31 communities in Vietnam (figure 1). Demographic and socioeconomic comparisons 


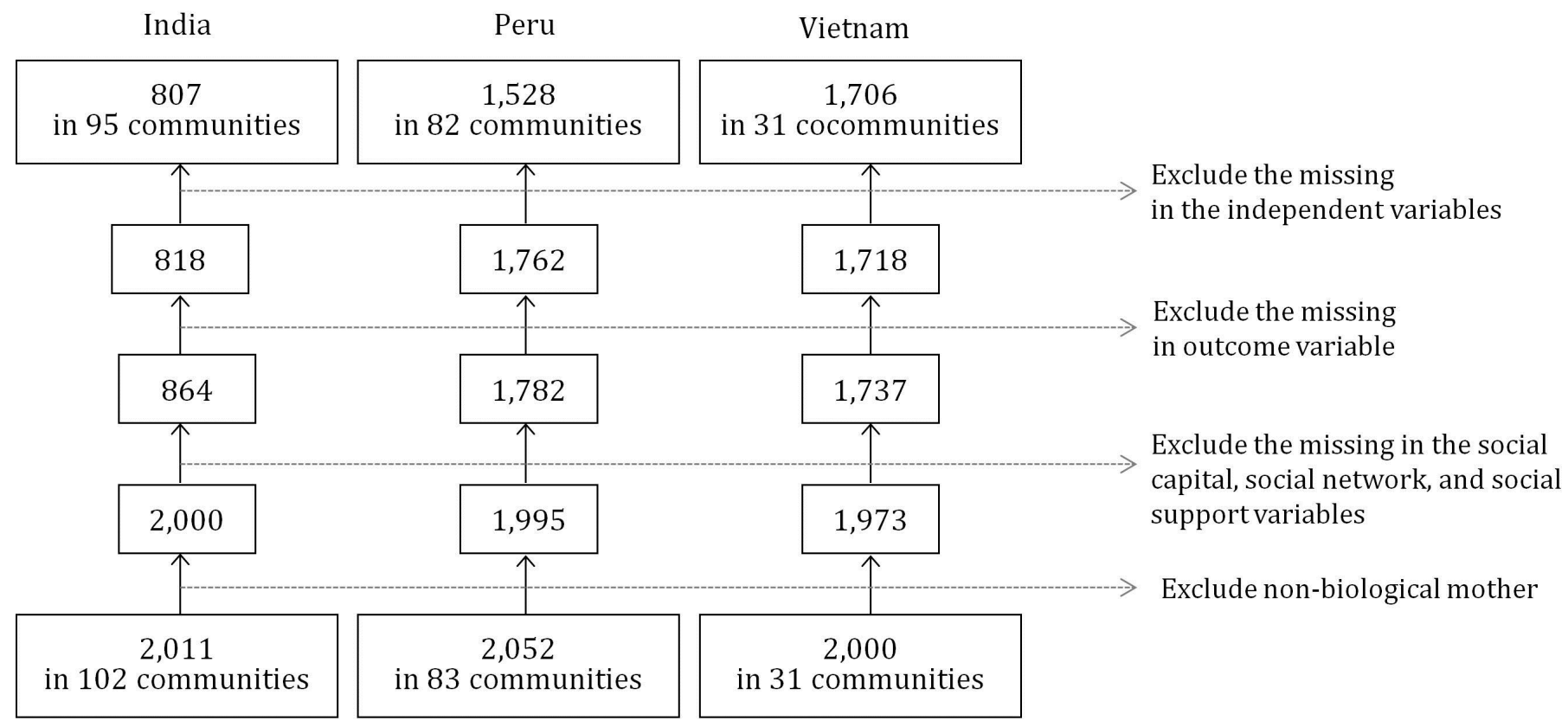

Figure 1 Flow chart of the final analytical sample sizes for India, Peru and Vietnam.

between the final analytic sample and the original sample are provided in online supplementary table 1 .

\section{Outcome and social capital variables}

The outcome variable of the study was infant birth weight measured in grams and used as a continuous variable in the main analyses. ${ }^{42}$ Low infant birth weight was defined by WHO criteria $(<2500 \mathrm{~g}) .^{43}$ Hospital, clinic or maternity home documents were used as the data source for infant birth weight where possible. If caretakers did not have these records, maternal recall was used to obtain infant birth weight. ${ }^{44}$ Studies have found that mothers in developing countries can recall birth weights accurately if the information was obtained at as early an age as possible. ${ }^{44-46}$

The Young Lives study used the Short Social Capital Assessment Tool (SASCAT) to quantitatively measure social capital. The tool was evaluated for construct validity in Vietnam and Peru using a range of methods, including factor analysis and qualitative cognitive interviews. ${ }^{34}{ }^{47}$ SASCAT is a shortened version of the Adapted Social Capital Tool developed by Harpham et $a l^{48}$ It measures three dimensions of network-based social capital at the individual level, that is, group membership, cognitive social capital and social support. Level of group membership, cognitive social capital and social support were operationalised with a similar approach used in the previous studies. ${ }^{49}$ Specifically, a total score of group membership was generated by summing the number of groups in which a mother was a member (yes/no). The maximum was seven group including work related/trade union group, community association or cooperative group, women's group, political group, religious group, credit or funeral group and sports group. The score was then categorised as none of the groups, membership in one group and membership in more than two groups.
Cognitive social capital was calculated by summing the number of 'yes' responses to three questions about a sense of belonging, mutual trust and getting along with each other in respondent's community and adding 1 for a 'no' response to another question related to unfavourable perception (whether there are people in your community trying to take advantage of you). Thus, the range of the score was $0-4$. As we assumed that the effect of maternal cognitive social capital would not present linearly, we grouped the score into three categories: low (0-1), medium (2-3) and high (4).

Finally, information about support received from groups in which respondents were members as well as information about social support received from specific types of individuals were combined to measure social support. If respondents responded affirmatively that they had a membership in a certain group, they were asked whether they had received support from that group in the previous year. In addition, respondent were asked whether they had received support from each of nine categories of individuals (eg, family, neighbours, friends, community leaders, politicians and so on). Thus, a total score of social support was calculated by adding the number of 'yes' responses to all of these questions. The possible score ranged from 0 to 16 and was then categorised as 'never received support', 'received support from 1 to 2 groups or individuals' and 'received support from $3+$ groups or individuals'. Cut-offs for categorisation were determined based on the frequency distribution. The same cut-offs were used in each country. The list of questions about each dimension of social capital is presented in online supplementary table 2.

\section{Other explanatory factors}

The selection of other explanatory factors to be included in this study was guided by a review of previous 
articles. ${ }^{16} 303537$ Mother's age at pregnancy was divided into 10-year intervals: younger than 19, 20-29 years, 30-39 years and older than 40 years. Mother's education was grouped into four categories: below primary (lowest), primary school (low), middle school (medium) and high school or above (high). Household wealth quintiles were calculated using information on 30 assets and housing characteristics and conducting a principal components analysis. ${ }^{50}$ Categorisation of ethnicity depended on the country. In India, categories included other castes (ethnic majority), backward caste, scheduled tribe and scheduled caste. In Peru, categories included Mestizo (ethnic majority) or other. In Vietnam, categories included Kinh (ethnic majority) and non-Kinh. Marital status was dichotomised into married and single, with the latter including divorced or separated, single and widowed. Antenatal care (at least one visit vs no visit), parity of child (first vs second or more) and infant sex were also recorded. All factors were also measured at individual level.

\section{Statistical analysis}

A two-level random intercept linear regression model was used to estimate the associations between maternal group membership, cognitive social capital and social support and infant birth weight for each country. We chose to use linear regression by operationalising birth weight as a continuous variable (rather than use logistic regression based on a binary outcome variable) because previous work has shown that the effect of social capital on health might be relatively small ${ }^{32}$ and we wanted to detect any small differences in infant birth weight among different levels of social capital. In addition, there was a non-convergence issue that might be caused by a small number of observations in a few categories for certain independent variables.

The first level of the model represented the individual (i) and the second level represented the community (j) as defined by local administrative boundaries. The model specified as follows:

$$
\begin{gathered}
Y_{i j}=\beta_{0 j}+B X_{i j}^{\prime}+R_{i j} \\
\beta_{0 j}=\gamma_{00}+U_{0 j}
\end{gathered}
$$

This model estimates the $Y_{i j}$ when adjusted for a vector $\left(X_{i j}^{\prime}\right)$ of the aforementioned independent variables measured at an individual level. $\beta_{0 j}$ indicates average intercept $\left(\gamma_{00}\right)$ plus community-dependent deviation $\left(U_{o j}\right)$. First, we examined the association between categories of group membership, cognitive social capital social support and birth weight. Considering that group membership, cognitive social capital and social support are conceptually distinct and that mean variance inflation factors were below two across the social capital indicators, we assumed that there was no problematic level of multicollinearity. Therefore, the model included all three indicators. Then, associations between specific types of group membership, social support and birth weight were investigated. Collinearity was detected between specific types of group membership and specific types of social support.
Therefore, we included types of group membership and types of social support in separate models. All models accounted for sociodemographic factors.

Multilevel models assume that the distribution at each level comes from am multivariate Gaussian distribution. ${ }^{51}$ We produced a normal score plot to assess this assumption, which showed that the data at each level were normally distributed for all three countries (online supplementary figure 1). All analyses were carried out by MlwiN 3.02.

\section{Patient and public involvement}

This study did not involve patients. Participants were households that have children aged between 6 months and 18 months at the time of recruitment in 2002. The findings from this study will be disseminated to the public via local media and civil society organisations.

\section{Results}

Table 1 presents the frequency of respondents and mean birth weight according to the categories of infant and maternal characteristics in three countries. Five hundred and sixteen and 1074 mothers in India and Vietnam, which corresponds to more than $60 \%$ of the sample in each country, and 802 mothers, which is more than $50 \%$ of the sample in Peru, were 20-29 years old when they were pregnant. Seven hundred and twenty-two, 1447 and 1517 mothers (about 90\% of the sample) received antenatal care during pregnancy in India, Peru and Vietnam, respectively. The distribution of education level is not consistent across countries. The mean infant birth weight from the Indian sample was lower than average birth weight from the other two countries, and the prevalence of low birth weight was also the highest in Indian sample.

Table 2 describes patterns of group membership, cognitive social capital and social support and mean infant birth weight for each country. The level of cognitive social capital, particularly the level of mutual trust and sense of belonging, were low in Peru compared with the other two countries. The proportion of women with membership in the women's group and women who received support from it was also lower in Peru than in India or Vietnam $(p<0.0001)$. None of the women in India had membership in a credit or funeral group nor in a sports group. Mean infant birth weight showed a statistically significant gradient according to the level of group membership in all three countries $(\mathrm{p}<0.0001)$.

Table 3 displays the associations between group membership, cognitive social capital and social support and infant birth weight from the adjusted multilevel regression model. Infant birth weight was positively associated with group membership in all three countries. In contrast, there was no association with cognitive social capital in all countries. A statistically significant association was found between social support and infant birth weight only in Vietnam. 
Table 1 Descriptive statistics of study samples from India, Peru and Vietnam and average infant birth weight (in grams)

\begin{tabular}{|c|c|c|c|c|c|c|}
\hline \multirow[b]{2}{*}{ Variable } & \multicolumn{2}{|l|}{ India } & \multicolumn{2}{|l|}{ Peru } & \multicolumn{2}{|l|}{ Vietnam } \\
\hline & N (\%) & $\begin{array}{l}\text { Mean birth } \\
\text { weight (SD) }\end{array}$ & N (\%) & $\begin{array}{l}\text { Mean birth } \\
\text { weight (SD) }\end{array}$ & N (\%) & $\begin{array}{l}\text { Mean birth } \\
\text { weight (SD) }\end{array}$ \\
\hline$\leq 19$ & 257 (31.9) & 1. $2720(557)$ & 341 (22.3) & $3120(487)$ & $195(11.4)$ & $2968(406)$ \\
\hline $20 \leq$ and $<30$ & $513(63.4)$ & $2783(538)$ & $802(52.5)$ & $3224(501)$ & $1074(62.9)$ & 3099 (432) \\
\hline $30 \leq$ and $<40$ & $37(4.6)$ & 2. $2758(611)$ & 335 (21.9) & $3224(505)$ & 408 (23.9) & 3177 (432) \\
\hline \multicolumn{7}{|l|}{ Antenatal care } \\
\hline No & 85 (10.5) & $2835(531)$ & $81(5.3)$ & $3013(602)$ & $189(11.1)$ & 3047 (470) \\
\hline Yes & $722(89.5)$ & 2754 (549) & 1447 (94.7) & 3205 (497) & 1517 (88.9) & 3111 (442) \\
\hline \multicolumn{7}{|l|}{ Mother's education } \\
\hline High or above & 317 (39.3) & $2827(516)$ & $262(17.1)$ & 3304 (513) & $116(6.8)$ & 3194 (435) \\
\hline \multicolumn{7}{|l|}{ Parity } \\
\hline Second or more & $805(99.8)$ & $2762(547)$ & Not available & & $1701(99.7)$ & $3104(446)$ \\
\hline First & $2(0.2)$ & $3000(707)$ & & & $5(0.3)$ & $2940(288)$ \\
\hline \multicolumn{7}{|l|}{ Marital status } \\
\hline Single & $7(0.9)$ & $2643(537)$ & 227 (14.9) & $3062(515)$ & $38(2.2)$ & 3021 (435) \\
\hline Married & $800(99.1)$ & 2764 (548) & $1301(85.1)$ & 3217 (499) & 1668 (97.8) & 3105 (445) \\
\hline \multicolumn{7}{|l|}{ Wealth status } \\
\hline The lowest & $161(20.0)$ & $2616(433)$ & $311(20.4)$ & $3070(511)$ & 339 (19.9) & $3011(451)$ \\
\hline Female & $369(45.7)$ & 2727 (531) & 760 (49.7) & 3166 (494) & $823(48.2)$ & $3052(423)$ \\
\hline \multicolumn{7}{|l|}{ Ethnicity (India) } \\
\hline Other castes & 254 (31.5) & $2845(551)$ & Not applicable & & Not applicable & \\
\hline Backward caste & $361(44.7)$ & 2737 (556) & & & & \\
\hline Scheduled tribe & $84(10.4)$ & 2624 (374) & & & & \\
\hline Scheduled caste & $108(13.4)$ & 2760 (599) & & & & \\
\hline \multicolumn{7}{|l|}{ Ethnicity (Peru) } \\
\hline Mestizo & \multirow{2}{*}{\multicolumn{2}{|c|}{ Not applicable }} & $1401(91.7)$ & $3194(501)$ & Not applicable & \\
\hline Others* & & & $127(8.3)$ & $3197(544)$ & & \\
\hline \multicolumn{7}{|l|}{ Ethnicity (Vietnam) } \\
\hline Kinh & Not applicable & & Not applicable & & 1696 (93.6) & $3115(441)$ \\
\hline Non-Kinh & & & & & $110(6.4)$ & $2935(475)$ \\
\hline $\begin{array}{l}\text { Prevalence of low birth } \\
\text { weight }\end{array}$ & $2762(16.7)$ & & $3194(5.4)$ & & $3104(5.0)$ & \\
\hline
\end{tabular}

Table 4 presents the associations between specific types of group membership and specific sources of social support and infant birth weight. Membership in a women's group was positively associated with infant birth weight consistently in all three countries. Additionally, a significant association between membership in a religious group and infant birth weight was found in Indian and Peru. In contrast, membership in a political group was negatively associated with infant birth weight in Peru while no significant association was seen in the other two countries. 
Table 2 Distribution of group membership, cognitive social capital and social support and average infant birth weight (in grams) in India, Peru and Vietnam

\begin{tabular}{|c|c|c|c|c|c|c|}
\hline \multirow[b]{2}{*}{ Variable } & \multicolumn{2}{|l|}{ India } & \multicolumn{2}{|l|}{ Peru } & \multicolumn{2}{|l|}{ Vietnam } \\
\hline & $\begin{array}{l}N \\
(\%)\end{array}$ & $\begin{array}{l}\text { Mean birth } \\
\text { weight (SD) }\end{array}$ & $\mathrm{N}(\%)$ & $\begin{array}{l}\text { Mean birth } \\
\text { weight (SD) }\end{array}$ & $\mathbf{N}(\%)$ & $\begin{array}{l}\text { Mean birth } \\
\text { weight (SD) }\end{array}$ \\
\hline \multicolumn{7}{|l|}{ Social group membership } \\
\hline $\begin{array}{l}\text { Work-related or trade union } \\
\text { group }\end{array}$ & $26(3.2)$ & & $5(0.3)$ & & $139(8.1)$ & \\
\hline $\begin{array}{l}\text { Community association or } \\
\text { cooperative group }\end{array}$ & $24(3.0)$ & & $93(6.1)$ & & $95(5.6)$ & \\
\hline Women's group & $162(20.2)$ & & $117(7.7)^{\star}$ & & $286(16.8)$ & \\
\hline Political group & $14(1.7)$ & & $26(1.7)$ & & $17(1.0)$ & \\
\hline Religious group & $4(0.6)$ & & $87(5.7)$ & & $11(0.6)$ & \\
\hline Credit or funeral group & $0(0)$ & & $4(0.3)$ & & $113(6.6)$ & \\
\hline Sports group & $0(0)$ & & $25(1.6)$ & & $5(0.3)$ & \\
\hline \multicolumn{7}{|c|}{ Total number of social group membership } \\
\hline None of the groups & $600(74.3)$ & $2739(510) \dagger$ & $1245(81.5)$ & $3169(491) \dagger$ & $1238(72.6)$ & $3081(445) \dagger$ \\
\hline 1 group & $185(22.9)$ & $2811(615) \dagger$ & $224(14.7)$ & $3277(532) \dagger$ & $315(18.5)$ & $3126(428.) \dagger$ \\
\hline $2+$ groups & $22(2.9)$ & $3000(854) \dagger$ & $59(3.9)$ & $3407(607) \dagger$ & $153(9.0)$ & $3236(459) \dagger$ \\
\hline \multicolumn{7}{|l|}{ Cognitive social capital } \\
\hline $\begin{array}{l}\text { Majority of people can be } \\
\text { trusted }\end{array}$ & $764(94.7)$ & & $536(35.1)$ & & $1437(84.2)$ & \\
\hline The majority of people get along & 759 & & $1042(68.2)$ & & $1565(91.7)$ & \\
\hline $\begin{array}{l}\text { Really feel part of the } \\
\text { community }\end{array}$ & $782(96.9)$ & & $244(16.0)^{\star}$ & & $1678(98.4)$ & \\
\hline Take advantage of you & $322(39.9)$ & & $899(58.8)$ & & $159(9.3)$ & \\
\hline \multicolumn{7}{|l|}{ Level of cognitive social capital } \\
\hline Low (0-1) & $20(2.5)$ & 2675 (639) & $343(22.5)$ & $3221(513)$ & $50(2.9)$ & $3016(500)$ \\
\hline Medium (2-3) & $350(43.3)$ & $2751(524)$ & $855(56.0)$ & $3212(510)$ & $337(19.8)$ & $3106(418)$ \\
\hline High (4) & $437(54.2)$ & $2776(564)$ & $330(21.6)$ & $3120(475)$ & $1319(77.3)$ & $3106(450)$ \\
\hline \multicolumn{7}{|l|}{ Support from group } \\
\hline $\begin{array}{l}\text { Work-related or trade union } \\
\text { group }\end{array}$ & $6(0.7)$ & & $3(0.2)$ & & $116(6.8)$ & \\
\hline $\begin{array}{l}\text { Community association or } \\
\text { cooperative group }\end{array}$ & $11(1.4)$ & & $34(2.2)$ & & $37(2.2)$ & \\
\hline Women's group* & $103(12.9)$ & & $46(3.0)$ & & $194(11.4)$ & \\
\hline Political group & $5(0.6)$ & & $14(0.9)$ & & $14(0.8)$ & \\
\hline Religious group & $2(0.3)$ & & $64(4.2)$ & & $8(0.5)$ & \\
\hline Credit or funeral group & $0(0)$ & & $3(0.2)$ & & $64(3.8)$ & \\
\hline Sports group & $0(0)$ & & $10(0.7)$ & & $5(0.3)$ & \\
\hline \multicolumn{7}{|l|}{ Support from individual } \\
\hline Family & $564(69.9)$ & & $972(63.6)$ & & $1,623(95.1)$ & \\
\hline Neighbours & $376(46.5)$ & & $281(18.4)$ & & $1332(78.1)$ & \\
\hline Friends & $134(16.6)$ & & $280(18.3)$ & & $1229(72.0)$ & \\
\hline Community leaders & $22(2.7)$ & & $29(1.9)$ & & $257(15.1)$ & \\
\hline Religious leaders & $5(0.6)$ & & $123(8.1)$ & & $21(1.2)$ & \\
\hline Political leaders & $11(1.4)$ & & $13(0.9)$ & & $2(0.1)$ & \\
\hline Government officials & $24(3.0)$ & & $73(4.8)$ & & $85(5.0)$ & \\
\hline
\end{tabular}

Continued 
Table 2 Continued

\begin{tabular}{|c|c|c|c|c|c|c|}
\hline \multirow[b]{2}{*}{ Variable } & \multicolumn{2}{|l|}{ India } & \multicolumn{2}{|l|}{ Peru } & \multicolumn{2}{|l|}{ Vietnam } \\
\hline & $\begin{array}{l}N \\
(\%)\end{array}$ & $\begin{array}{l}\text { Mean birth } \\
\text { weight (SD) }\end{array}$ & N (\%) & $\begin{array}{l}\text { Mean birth } \\
\text { weight (SD) }\end{array}$ & N (\%) & $\begin{array}{l}\text { Mean birth } \\
\text { weight (SD) }\end{array}$ \\
\hline $\begin{array}{l}\text { Non Government Organizations } \\
\text { charities }\end{array}$ & $13(1.6)$ & & $87(5.7)$ & & $103(6.0)$ & \\
\hline \multicolumn{7}{|l|}{ Total number of supports received } \\
\hline Never received & $170(21.0)$ & 2739 (576) & $459(30.0)$ & 3161 (532) & $52(3.0)$ & $2852(571)$ \\
\hline $\begin{array}{l}\text { Support from } 1 \text { to } 2 \text { groups or } \\
\text { individuals }\end{array}$ & 475 (58.9) & 2772 (521) & $810(53.0)$ & 3206 (486) & 447 (26.2) & $3132(454)$ \\
\hline $\begin{array}{l}\text { Support from } 3+\text { groups or } \\
\text { individuals }\end{array}$ & $162(20.1)$ & 2758 (600) & 259 (17.0) & 3219 (509) & $1207(70.8)$ & 3104 (433) \\
\hline
\end{tabular}

*Significant difference in proportion between countries at $p<0.0001$ in a $\chi^{2}$ test.

†Significant difference in mean birth weight between levels of group membership at $p<0.0001$ in a $\chi^{2}$ test.

NGO, Non Government Organisatios.

Findings about associations between specific sources of social support and infant birth weight were mixed. Support from a religious group showed a strong positive association with infant birth weight in India and Peru, while it was negatively associated with infant birth weight in Vietnam. Support from a community association, from a cooperative group and from a religious group were positively associated with infant birth weight in Peru only. Support from family was positively associated with infant birth weight in Vietnam only.

The associations between infant birth weight and other potential factors such as maternal age at pregnancy, receipt of antenatal care, marital status and education varied across countries. However, wealth status exhibited a robust positive gradient with infant birth weight in all three countries. This was extracted from models presented in model 3 that examined the association between the composite score of social capital and birth weight (online supplementary table 3 ).

\section{Discussion}

This study examined associations between maternal social group membership, cognitive social capital and social support and infant birth weight and also investigated how different types of group membership and different sources of social support were associated with infant birth weight in three LMICs. A few findings should be emphasised.

First, overall level of maternal social group membership and infant birth weight was consistently associated with infant birth weight in a positive direction for all three countries. In contrast, the association between cognitive

Table 3 Associations between maternal group membership, cognitive social capital and social support and infant birth weight in India, Peru and Vietnam

\begin{tabular}{|c|c|c|c|c|c|c|c|c|c|}
\hline \multirow[b]{2}{*}{ Variable } & \multicolumn{3}{|l|}{ India } & \multicolumn{3}{|l|}{ Peru } & \multicolumn{3}{|c|}{ Vietnam } \\
\hline & b & (SE) & $P$ value & b & (SE) & $P$ value & b & (SE) & $P$ value \\
\hline \multicolumn{10}{|c|}{ Social group membership (ref=none) } \\
\hline $2+$ groups & 276.3 & $(118.5)$ & 0.020 & 233.5 & $(67.4)$ & 0.001 & 120.0 & $(39.2)$ & 0.002 \\
\hline \multicolumn{10}{|c|}{ Cognitive social capital (ref=low) } \\
\hline High & 108.6 & $(125.1)$ & 0.337 & -71.3 & $(38.2)$ & 0.062 & 69.2 & $(63.3)$ & 0.274 \\
\hline \multicolumn{10}{|c|}{ Social support (ref=never received) } \\
\hline $\begin{array}{l}\text { Support from } 1 \text { to } 2 \\
\text { groups or individuals }\end{array}$ & 57.1 & $(51.5)$ & 0.267 & 14.0 & (29.1) & 0.63 & 263.5 & $(64.1)$ & $<0.001$ \\
\hline $\begin{array}{l}\text { Support from 3+ } \\
\text { groups or individuals }\end{array}$ & -6.5 & $(65.9)$ & 0.921 & 5.7 & $(39.6)$ & 0.886 & 206.4 & (62.7) & 0.001 \\
\hline
\end{tabular}

All dimensions of social capital were included together in a model.

The model was adjusted for maternal age at pregnancy, maternal education level, household wealth level, ethnicity, marital status, parity, antenatal care and infant gender. 


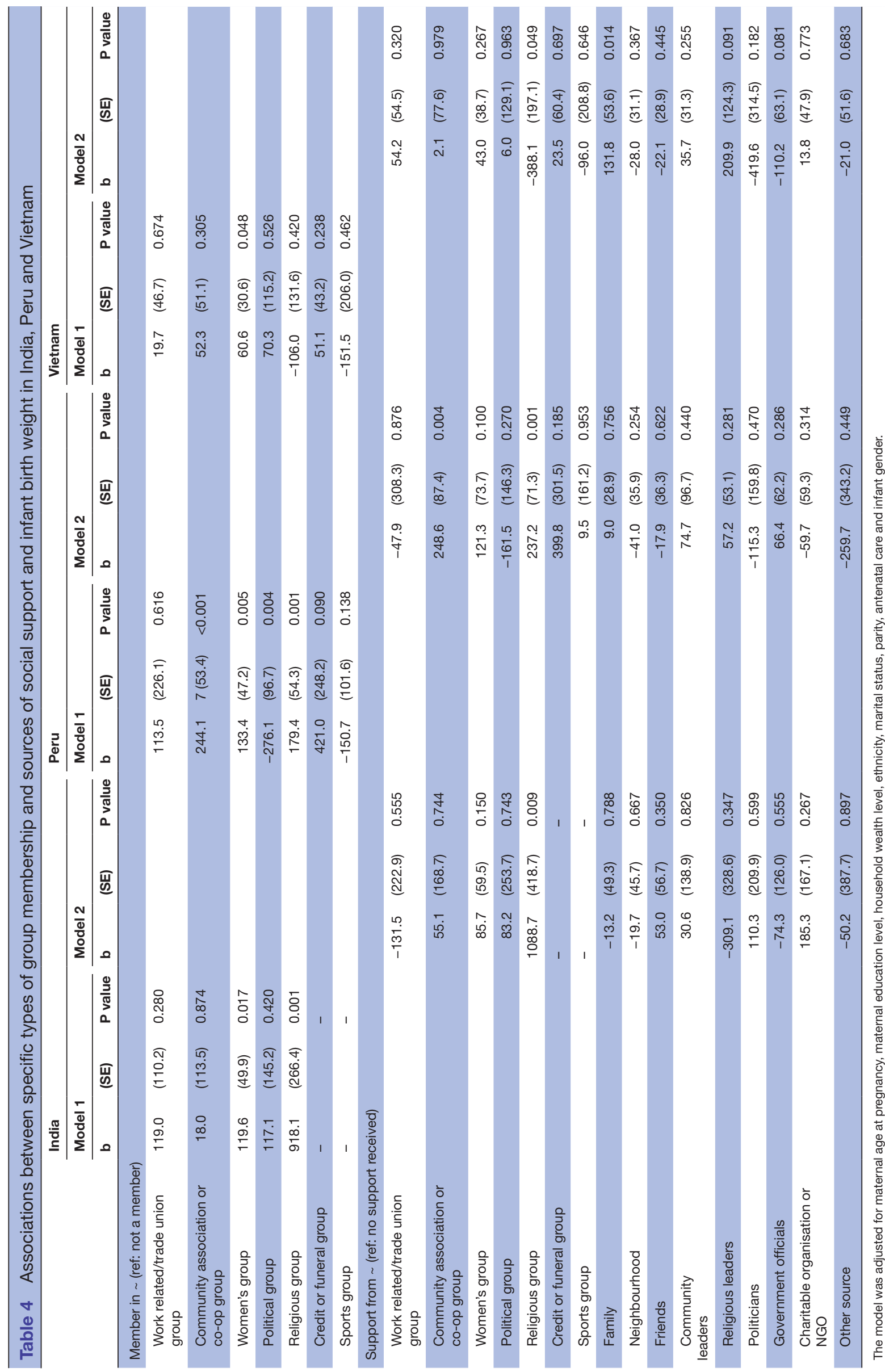


social capital and infant birth weight was not statistically significant in all three countries. Current findings are supported by results from previous studies on social capital and birth outcomes. For example, Baker et $a l^{15}$ reported a non-significant association between social cohesion and collective efficacy and low birth weight in India. In Kritsotakis et al, ${ }^{16}$ feeling of safety and tolerance to diversity were not associated with any of birth outcomes such as preterm birth, small for gestational age, fetal weight growth restriction, fetal weight, fetal length and head circumference. However, studies using measures of cognitive social capital from the Young Lives study have found them to be associated with other child outcomes such as height and mental health. ${ }^{13}$ A definitive explanation for this different pattern of association depending on the outcome is lacking. Although De Silva and Harpham ${ }^{13}$ suggest that higher cognitive social capital may foster a mother's psychological well-being and ability to cope and, thus, enable them to better care for their child, this cognitive support may not be strong enough to improve care for the fetus during pregnancy. Discrepancies regarding the role of cognitive social capital on infant health needs further research elucidation.

Second, although the overall level of maternal group membership showed a positive gradient with infant birth weight in Peru, membership in a political group showed an inverse association with infant birth weight. Similarly, despite the positive association between the overall level of support and infant birth weight, support from a religious group was negatively associated with infant birth weight in Vietnam. Caution is needed when interpreting these results given the cross-sectional nature of the data and that the number of respondents who were members in a political group and who received support from a religious group were small. However, the downside of social capital is worth discussing. Social capital, usually praised for its benefit, can cut both ways as spheres of responsibility across social groups, local communities, family and neighbours vary according to the social, economic or political context of the society. ${ }^{52}$ For example, tightly knit and cohesive communities may lead to exclusion of outsiders, excessive claims made on group members sometimes at a high personal cost or restrictions on individual freedoms. ${ }^{5354}$

Our result is, in part, in line with a study on birth outcomes in Greece where for every unit increase in maternal group participation, there was an estimated increase in the risk of preterm birth. ${ }^{16}$ The authors suggested that more participation may be linked to more exposure to social and/or environmental stressors. A couple of studies have demonstrated the downside of social capital on other outcomes through empirical analyses. De Silva ${ }^{55}$ found a significant association between maternal group membership and increased odds of maternal common mental disorder in Andhra Pradesh of India. She suggested that participation in the women's group that is mainly based on microcredit schemes may be stressful to the poor women due to their inability to make a profit using loans from the scheme, thus, not being able to repay the loans. Hurtado et $a \tilde{l}^{\tilde{6}}$ demonstrated a negative association between non-electoral participation in political group and self-rated health in Columbia, presumably due to the effect of political violence. In a study by Mitchell and LaGory, ${ }^{57}$ bonding social capital was shown to be positively associated with mental distress in an impoverished and racially segregated urban neighbourhood in the USA.

Peru, as did many other countries in Latin America, introduced democratic governance during the 1980s. However, it has still suffered from long-term political instability and suppression of civil society including suppression of political groups. ${ }^{58}{ }^{59}$ In addition, although there has been increased female empowerment in Peru, men are still more likely to hold positions of power and prestige in political environment, while women carry the burden of implementing chores that is is time-consuming and confer less prestige. ${ }^{60}$ It is likely that participating in a political group within a period of oppression combined with the lower status of women within such a group is unfavourable for a pregnant woman's well-being. Analysis based on a larger sample size and qualitative studies are needed to further understand this negative association.

Third, membership in a women's group was consistently associated with higher birth weight in all three countries. Women's groups are a self-organised group who undertake various activities such as skills training to fundraising. ${ }^{61}$ This gathering provides important sources for bonding social capital where mothers share information related to health and exchange emotional or material support. Level of adaptation to encouraged health behaviour or amount of shared information obtained is higher through voluntary participation in a social group than through just education because of its nature of the interaction. ${ }^{62}$ Although there is some evidence concerning a harmful effect from the extra burden of participating in a women's group, ${ }^{32} 5560$ it may depend on country or community context. Generally, a women's group is expected to have a protective role for birth outcomes through knowledge transfer and information sharing related to pregnancy and delivery during interaction with other members. ${ }^{63}$

The final key finding is that, in Vietnam, support from individuals especially from family may be important for preventing mothers from having low weight babies. This finding is backed up by another study using the same data source, which found a positive association between maternal social support from an informal network and nutritional status of 1-year-old children in Vietnam. ${ }^{32}$ The informal network is a strong feature of Vietnamese society to the extent that more than $95 \%$ of mothers have received support from family and more than $78 \%$ and $72 \%$ of mothers have received support from neighbours and friends, respectively, which is much higher compared with informal support levels in India and Peru. Vietnam's Confucian tradition promotes trust in a comparatively narrow realm of family that offers extensive support. ${ }^{6465}$ 
This support may influence infant birth weight by provision of emotional care, knowledge about prenatal care or physical and material assistance. ${ }^{30} 32$

Our exploratory analyses provide a comprehensive picture of the associations between maternal social capital indicators and infant birth weight in three very different cultural contexts. This study implies that although some forms of social capital may generally be associated with infant birth weight in a positive direction, specific sources of social capital may have different associations with infant birth weight depending on the social, political or cultural specificity of the country. Results suggest many challenging questions requiring for further research to answer. To tailor a specific intervention for each society, additional research is needed on the detailed mechanisms through which social capital influences birth weight outcomes in each country.

\section{Limitations}

This study should be interpreted with care due to several limitations. First, a substantial proportion of observations were excluded due to missings on the dependent variable. However, we did not consider multiple imputation (MI) method because MI cannot improve on complete case analysis when missing happens on the dependent variable with no missing data on any of the independent variables, and there are no strongly correlated auxiliary predictors. Although comparison of descriptive statistics between the dropped sample and the original sample suggest that the missings are random, there still is a chance of bias arising from the missings. Second, the cross-sectional design limits causal inference. It is possible that some of the associations are attributable to reverse causality. For example, healthy pregnant mothers may be more likely to participate in a social group. Third, while infant birth weight could be affected by social capital all the way through the gestational period, the Young Lives study asked about maternal social capital during the last 12 months before the survey time. Some mothers might have started participating in a certain group or receiving support after the baby was born. How this would affect the result can cut both ways. While mothers with a healthy baby may be more likely to attend a social group, it is also possible that mothers with a less healthy baby join a social group to seek help. Fourth, there might be omitted variable bias as we did not have information about maternal health status such as genetic disease or maternal obstetric condition. However, considering that the prevalence of congenital defect is usually low, the effect of this kind of omitted variable bias is assumed to be marginal. Fifth, the data for the study are more than 15 years old, which may lead to questions about whether the associations are still valid within current contexts. However, it is expected that changes in associated factors over time do not harm the validity of the original findings. In addition, the results of our study may offer lessons to other LMIC contexts currently experiencing situations that India, Peru and Vietnam experienced 15 years ago. Sixth, though SASCAT has been validated in Peru and Vietnam, no validation has yet been conducted in Andhra Pradesh. However, the questions about group type or support type are relatively conceptually clear, and therefore, chances are low that people would interpret the questions differently by country. Lastly, Young Lives study adopted oversampling for poor sites, and data from India were drawn only from the state of Andhra Pradesh. Although sample selection was designed in a way that they can provide opportunities to compare poor and better-off by avoiding comprising the sample exclusively of poor children and minimise the chance that the results of the study would be rejected on the grounds of not being representative, care should be given to when discussing the results as applied to the entire population.

\section{CONCLUSION}

Results from our study revealed that although the overall level of social capital is positively associated with the birth weight, specific type of membership or social support may play a negative role for infant birth weight within a given cultural context. Policy efforts to strengthen social capital should consider local societal and cultural dynamics to identify a potentially helpful source of social capital. Specific ways of intervening on maternal social capital need to be tailored for each society rather than transplanting interventions from country to country.

\section{Author affiliations}

1JW LEE Center for Global Medicine, Seoul National University College of Medicine, Seoul, Republic of Korea

${ }^{2}$ Takemi Program in International Health, Department of Global Health and Population, Harvard T.H. Chan School of Public Health, Boston, MA, USA

${ }^{3}$ Department of Social and Behavioral Sciences, Harvard T.H. Chan School of Public Health, Boston, MA, USA

${ }^{4}$ Department of Human and Organizational Development, Peabody College, Vanderbilt University, Nashville, TN, USA

${ }^{5}$ Vanderbilt Institute of Global Health, Vanderbilt University Medical Center, Nashville, TN, USA

${ }^{6}$ National Assembly Futures Institute, Seoul, Republic of Korea

${ }^{7}$ Harvard Center for Population and Development Studies, Harvard T.H. Chan School of Public Health, Boston, MA, USA

Contributors $\mathrm{H}-\mathrm{YL}$ conceived the research question, performed statistical analysis and data interpretation and wrote the manuscript. J0 coconceived the research question, interpreted data, revised paper and provided overall supervision. JMP and $\mathrm{JH}$ provided critical review and revised the paper. SVS also provided critical review and intellectual input. All authors approved the final version.

Funding The authors have not declared a specific grant for this research from any funding agency in the public, commercial or not-for-profit sectors.

Competing interests None declared.

Patient consent for publication Not required.

Provenance and peer review Not commissioned; externally peer reviewed.

Data availability statement Data are available from the UK Data Service website (at https://discover.ukdataservice.ac.uk/series/?sn=2000060). Users are required to register and apply for a password with the UK Data Service and sign a confidentiality agreement before getting access to the data. Also, users are asked to inform the UK Data Service and Young Lives of analysis or publication resulting from their work with the dataset.

Open access This is an open access article distributed in accordance with the Creative Commons Attribution Non Commercial (CC BY-NC 4.0) license, which 
permits others to distribute, remix, adapt, build upon this work non-commercially, and license their derivative works on different terms, provided the original work is properly cited, appropriate credit is given, any changes made indicated, and the use is non-commercial. See: http://creativecommons.org/licenses/by-nc/4.0/.

\section{ORCID iDs}

Hwa-Young Lee http://orcid.org/0000-0003-2591-1436

Jessica M Perkins http://orcid.org/0000-0002-5475-8816

Jongho Heo http://orcid.org/0000-0002-6405-3860

\section{REFERENCES}

1 Overpeck MD, Moss AJ, Hoffman HJ, et al. A comparison of the childhood health status of normal birth weight and low birth weight infants. Public Health Rep 1989;104:58-70.

2 Valdez R, Athens MA, Thompson GH, et al. Birthweight and adult health outcomes in a biethnic population in the USA. Diabetologia 1994;37:624-31.

3 Barker DJP, Osmond C, Winter PD, et al. Weight in infancy and death from ischaemic heart disease. The Lancet 1989;334:577-80.

4 Hack M, Caron B, Rivers A, et al. The very low birth weight infant: the broader spectrum of morbidity during infancy and early childhood. $J$ Dev Behav Pediatr 1983:4:243-9.

5 Shapiro S, McCormick MC, Starfield BH, et al. Relevance of correlates of infant deaths for significant morbidity at 1 year of age. Am J Obstet Gynecol 1980;136:363-73.

6 Mutala JA. Relationship between maternal anthropometry, sociodemographic factors and infant's anthropometry at birth: The case of the provincial general hospital. Nakuru, Kenya: Egerton University, 2011.

7 Khoury MJ, Erickson JD, Cordero JF, et al. Congenital malformations and intrauterine growth retardation: a population study. Pediatrics 1988;82:83-90.

8 Salmasi G, Grady R, Jones J, et al. Environmental tobacco smoke exposure and perinatal outcomes: a systematic review and metaanalyses. Acta Obstet Gynecol Scand 2010;89:423-41.

9 Cleveland LM, Minter ML, Cobb KA, et al. Lead hazards for pregnant women and children: Part 1: immigrants and the poor shoulder most of the burden of lead exposure in this country. Part 1 of a two-part article details how exposure happens, whom it affects, and the harm it can do. Am J Nurs 2008;108:40-9.

10 McConnachie A, Haig C, Sinclair L, et al. Birth weight differences between those offered financial voucher incentives for verified smoking cessation and control participants enrolled in the cessation in pregnancy incentives trial (CPIT), employing an intuitive approach and a Complier average causal effects (CACE) analysis. Trials 2017;18:337.

11 Morgen CS, Bjørk C, Andersen PK, et al. Socioeconomic position and the risk of preterm birth--a study within the Danish National Birth Cohort. Int J Epidemiol 2008;37:1109-20.

12 Habibov N, Fan L, Campbell D, et al. Effect of prenatal care frequency, timing, and quality on child birth weight in Tajikistan. World Med Health Policy 2017;9:89-102.

13 De Silva MJ, Harpham T. Maternal social capital and child nutritional status in four developing countries. Health Place 2007;13:341-55.

14 Schölmerich VLN, Erdem Özcan, Borsboom G, et al. The association of neighborhood social capital and ethnic (minority) density with pregnancy outcomes in the Netherlands. PLoS One 2014;9:e95873.

15 Baker KK, Story WT, Walser-Kuntz E, et al. Impact of social capital, harassment of women and girls, and water and sanitation access on premature birth and low infant birth weight in India. PLoS One 2018;13:e0205345

16 Kritsotakis G, Vassilaki M, Chatzi L, et al. Maternal social capital and birth outcomes in the mother-child cohort in Crete, Greece (Rhea study). Soc Sci Med 2011;73:1653-60.

17 Kawachi I, Berkman L, cohesion S. Social capital, and health. In: Social epidemiology, 2000: 174-90.

18 Kawachi I, Subramanian SV, Kim D. Social capital and health. Social capital and health: Springer, 2008: 1-26.

19 Veenstra G, capital S. Social capital, Ses and health: an individuallevel analysis. Soc Sci Med 2000;50:619-29.

20 Berkman LF, Glass T, et al. Social integration, social networks, social support, and health. Social epidemiology 2000;1:137-73.

21 Lochner K, Kawachi I, Kennedy BP. Social capital: a guide to its measurement. Health Place 1999:5:259-70.

22 Putnam RD. E pluribus Unum: diversity and community in the twenty-first century the 2006 Johan Skytte Prize Lecture. Scan Polit Stud 2007;30:137-74
23 Forsman AK, Nyqvist F, Schierenbeck I, et al. Structural and cognitive social capital and depression among older adults in two Nordic regions. Aging Ment Health 2012;16:771-9.

24 Lin N. Building a network theory of social capital. Social capital: Routledge, 2017: 3-28.

25 Chow WS, Chan LS, network S. Social network, social trust and shared goals in organizational knowledge sharing. Information \& Management 2008;45:458-65.

26 Dunkel-Schetter C, Sagrestano L, Feldman P, et al. Social support and pregnancy: a comprehensive review focusing on ethnicity and culture. Handbook of social support and family relationships. New York: Plenum Press, 1996.

27 Oakley A. Is social support good for the health of mothers and babies? J Reprod Infant Psychol 1988;6:3-21.

28 Cobb S. Social support as a moderator of life stress. Psychosom Med 1976;38:300-14.

29 Cohen S, Wills TA, Stress WTA. Stress, social support, and the buffering hypothesis. Psychol Bull 1985;98

30 Hoffman S, Hatch MC, Stress HMC. Stress, social support and pregnancy outcome: a reassessment based on recent research. Paediatr Perinat Epidemiol 1996;10:380-405

31 Kouvonen A, Oksanen T, Vahtera J, et al. Work-place social capital and smoking cessation: the Finnish public sector study. Addiction 2008;103:1857-65.

32 Harpham T, De Silva MJ, Tuan T. Maternal social capital and child health in Vietnam. J Epidemiol Community Health 2006;60:865-71.

33 Folland S. Does "community social capital" contribute to population health? Soc Sci Med 2007:64:2342-54.

34 De Silva MJ, Harpham T, Tuan T, et al. Psychometric and cognitive validation of a social capital measurement tool in Peru and Vietnam. Soc Sci Med 2006;62:941-53.

35 Feldman PJ, Dunkel-Schetter C, Sandman CA, et al. Maternal social support predicts birth weight and fetal growth in human pregnancy. Psychosom Med 2000;62:715-25.

36 Buka SL, Brennan RT, Rich-Edwards JW, et al. Neighborhood support and the birth weight of urban infants. Am J Epidemiol 2003;157:1-8.

37 Nkansah-Amankra S, Dhawain A, Hussey JR, et al. Maternal social support and neighborhood income inequality as predictors of low birth weight and preterm birth outcome disparities: analysis of South Carolina pregnancy risk assessment and monitoring system survey, 2000-2003. Matern Child Health J 2010;14:774-85.

38 Wakeel F, Wisk LE, Gee R, et al. The balance between stress and personal capital during pregnancy and the relationship with adverse obstetric outcomes: findings from the 2007 Los Angeles Mommy and baby (lamb) study. Arch Womens Ment Health 2013;16:435-51.

39 Barnett I, Ariana P, Petrou S, et al. Cohort profile: the young lives study. Int J Epidemiol 2013;42:701-8.

40 Lives Y. Young lives methods guide: sampling. Available: http://www. younglives.org.uk/files/methods-guide/methods-guide-sampling

41 Outes-Leon I, Dercon S. Survey attrition and attrition bias in young lives. In: Young lives technical note. 5, 2008.

42 Selvin S, Abrams B. Analysing the relationship between maternal weight gain and birthweight: exploration of four statistical issues. Paediatr Perinat Epidemiol 1996;10:220-34.

43 Unicef, Organization WH. Low birthweight: country. regional and global estimates 2004.

44 Study YL. Summary of the young lives conceptual framework. Round1. UK data Archive study number 5307. U.K.: Department of International Development, University of Oxford, 2003.

45 Gofin R, Neumark YD, Adler B. Birthweight recall by mothers of Israeli children. Public Health 2000;114:161-3.

46 Gaskin P, Walker SP, Forrester TE, et al. The validity of recalled birthweight in developing countries. Am J Public Health 1997:87:114-14.

47 Tuan T, Harpham T, Huong N, et al. Measuring social capital and mental health in Vietnam: a validity study, 2005

48 Harpham T, Grant E, Thomas E. Measuring social capital within health surveys: key issues. Health Policy Plan 2002;17:106-11.

49 De Silva MJ, Huttly SR, Harpham T, et al. Social capital and mental health: a comparative analysis of four low income countries. Soc Sci Med 2007;64:5-20.

50 UNFPA. Report on the status of elderly in selected states of India 2011: building a knowledge base on ageing in India. New Delhi, India: United Nations Population Fund, 2012.

51 Jones K, Subramanian S. Developing multilevel models for analysing contextuality, heterogeneity and change using MLsiN 2.2. 1. Bristol: Centre for Multilevel Modelling:University of Bristol, 2012.

52 Kääriäinen J, Lehtonen $\mathrm{H}$. The variety of social capital in welfare state regimes - a comparative study of 21 countries. European Societies 2006:8:27-57. 
53 Portes A. Social capital: its origins and applications in modern sociology. Annu Rev Sociol 1998;24:1-24.

54 Thieme S. Social networks and migration: far West Nepalese labour migrants in Delhi: Lit Verlag Münster, 2006.

55 De Silva MJ. Context and composition?: social capital and maternal mental health in low income countries. In: London School of Hygiene \& Tropical Medicine, 2005.

56 Hurtado D, Kawachi I, Sudarsky J. Social capital and self-rated health in Colombia: the good, the bad and the ugly. Soc Sci Med 2011;72:584-90.

57 Mitchell CU, LaGory M. Social capital and mental distress in an impoverished community. City Community 2002;1:199-222.

58 Burt J. Political violence and the authoritarian state in Peru: silencing civil society. Springer, 2016.

59 Arce M. Political violence and presidential approval in Peru. J Polit 2003;65:572-83.
60 De Silva MJ, Harpham T, Huttly SR, et al. Understanding sources and types of social capital in Peru. Community Dev $J$ 2007;42:19-33.

61 Cueto S, Guerrero G, León J, et al. Social Capital and Education in Urban and Rural Peru. In: Young lives working paper, 2004.

62 Bolam A, Manandhar DS, Shrestha P, et al. The effects of postnatal health education for mothers on infant care and family planning practices in Nepal: a randomised controlled trial. BMJ 1998;316:805-11.

63 Manandhar DS, Osrin D, Shrestha BP, et al. Effect of a participatory intervention with women's groups on birth outcomes in Nepal: cluster-randomised controlled trial. The Lancet 2004;364:970-9.

64 Jones GW. Population and the family in Southeast Asia. J Southeast Asian Stud 1995;26:184-95.

65 Van Bich P. The Vietnamese family in change: the case of the red River delta. Routledge, 2013. 